\title{
CURSOS DE LICENCIATURA: A prática dos acadêmicos de Letras e Geografia
}

Marilene Marzari Hidelberto de Souzsa Ribeiro ${ }^{*}$

Este estudo, a respeito das práticas de ensino, está ligado às nossas trajetórias profissionais, tanto na Educação Básica, quanto em cursos de licenciatura no Ensino Superior. Isso possibilitou desenvolver a pesquisa, com o propósito de desencadear discussões em relação às práticas de ensino desenvolvidas pelos acadêmicos dos cursos de Geografia e Letras, durante a realização do estágio supervisionado, no ensino fundamental. O motivo deste estudo está relacionado ao período em que atuamos na Educação Básica quando, entre muitos reclamos, um era recorrente e estava relacionado à prática de ensino dos professores, principalmente, os referentes aos aportes teórico-metodológicos necessários ao desempenho das atividades relacionadas ao ensino que resultem em aprendizagem por parte dos alunos.

Partimos do princípio de que a aprendizagem dos alunos da Educação Básica possui estreita relação com a formação acadêmica dos professores; por isso, a necessidade de investigar, para discutir estratégias de intervenção, tanto na formação inicial dos acadêmicos quanto na continuada dos docentes que atuam com a formação de professores. Os dados estatísticos referentes às avaliações, tanto macro quanto micro, indicam fragilidades significativas em relação à aprendizagem dos alunos da Educação Básica, o que justifica a necessidade de estudos que possam contribuir para os avanços na qualidade da aprendizagem, em todos os níveis de ensino. Nesse sentido, a presente pesquisa realizada partiu da seguinte problemática: como os acadêmicos dos cursos de licenciatura em Letras e em Geografia desenvolvem as práticas de ensino, junto aos alunos dos anos finais do ensino fundamental, nas escolas da rede estadual de Barra do Garças, MT, durante a realização da regência, no estágio supervisionado?

O estudo tinha como objetivo principal, justamente, analisar as práticas de ensino desenvolvidas por tais acadêmicos, durante a regência, no estágio supervisionado, realizada nos anos finais do ensino fundamental, nas escolas da rede estadual em Barra do Garças, MT. Os objetivos

\footnotetext{
${ }^{(*)}$ Marilene Marzari. Doutora em Educação pela Pontifícia_Universidade Católica de Goiás (PUC-GO); professora nos Cursos de licenciatura do Campus Universitário do Araguaia (UFMT). E-mail: marilenemarzari@uol.com.br.

Hidelberto de Souzsa Ribeiro. Doutor em Sociologia pela Universidade Paulista Júlio de Mesquita (Unesp); atua nos Cursos de Licenciatura e Bacharelado do Campus Universitário do Araguaia (UFMT). E-mail: hidelbertos@uol.com.br.
} 
específicos consistiram em conhecer os planos de aula desenvolvidos pelos acadêmicos; acompanhar os acadêmicos durante a regência no estágio supervisionado; observar se realmente ocorria a aprendizagem dos alunos em relação aos conteúdos ensinados; realizar, com os acadêmicos, a avaliação, em relação à experiência docente vivenciada durante a regência e identificar as contradições entre a práxis pedagógica e o ensino na formação inicial - cursos de licenciatura em Letras e Geografia.

Para isso, utilizamo-nos da pesquisa qualitativa que, segundo Lüdke e André (1986), possibilita um contato direto e prolongado do pesquisador com o objeto de pesquisa e auxilia na descrição dos acontecimentos. Nessa pesquisa a intenção consistiu em averiguar as relações didáticopedagógicas que envolvem os acadêmicos/estagiários e os alunos, no decorrer das aulas. Para isso, os procedimentos de observação, de entrevista semiestruturada e de análise de documentos possibilitaram uma análise das práticas de ensino desenvolvidas pelos acadêmicos dos referidos cursos.

A observação in loco contribuiu para o levantamento de informações necessárias no sentido de conhecer como os acadêmicos/estagiários planejavam as aulas, organizavam o espaço, utilizavam os recursos e inseriam os alunos em atividade de aprendizagem. Além de perceber como os alunos lidavam com o conhecimento, isto é, se faziam intervenções, questionamentos, estabeleciam relações, faziam generalizações, entre outras práticas fundamentais para o desenvolvimento do pensamento cognitivo.

A observação começou a ser realizada no final de 2013, quando o projeto foi cadastrado junto à Pró-reitoria de Ensino e Pesquisa (ProPEq) e a rede estadual encerrou uma paralisação de mais de dois meses. Observamos, no final de 2013 e início de 2014, a prática dos acadêmicos do Curso de Geografia. O Curso de Licenciatura em Letras, em função da paralisação, desenvolveu a regência na própria universidade, na qual os alunos foram organizados em duplas e/ou trios e apresentaram temas referentes aos gêneros literários e à língua portuguesa para os poucos colegas e os dois professores responsáveis pelo estágio. O acompanhamento da regência fez com que tivéssemos uma ideia de como seriam organizadas e ministradas as aulas de língua portuguesa no ensino fundamental.

Outro procedimento foi a entrevista

[...] utilizada para recolher dados descritivos na linguagem do próprio sujeito, permitindo ao investigador desenvolver intuitivamente uma ideia sobre a maneira como os sujeitos interpretam aspectos do mundo. (BOGDAN; BIKLEN, 1994, p. 134). 
As entrevistas com os acadêmicos versaram sobre o planejamento das aulas, o exercício da docência, os conteúdos ministrados, a relação com os alunos, o processo de aprendizagem e as contribuições do curso para a formação docente.

A análise documental “[...] se constitui numa técnica valiosa de abordagem de dados qualitativos, seja complementando as informações obtidas por outras técnicas, seja desvelando aspectos novos de um tema ou problema”. (LUDKE; ANDRÉ, 1986, p. 38). Nessa pesquisa, partimos da análise de documentos, como o parecer para a formação docente, as diretrizes curriculares e os planos de ensino dos acadêmicos/estagiários. Somou-se a esses procedimentos um questionário para levantar dados sobre a vida pessoal, formativa e profissional dos acadêmicos.

Nessa pesquisa, utilizamos de uma literatura que trata da formação inicial, do estágio supervisionado, da teoria histórico-cultural e da didática desenvolvimental que discute a necessidade de uma sólida formação teórica e didática, a fim de que se possa mediar a formação do pensamento teórico, necessário ao desenvolvimento cognitivo dos alunos.

\section{FORMAÇÃO INICIAL: PRÁTICAS DE ENSINO NA PREPARAÇÃO DE PROFESSORES}

As discussões a respeito das práticas de ensino têm relação com a criação dos cursos de licenciatura, no final da década de trinta, quando se cria o curso de didática ${ }^{1}$ para a preparação de professores. Com a aprovação do Parecer n. 292/62 do Conselho Federal de Educação, foram criadas as disciplinas de didática e prática de ensino, em forma de estágio supervisionado. Nessa configuração, a prática era colocada no final dos cursos, evidenciando a dicotomia existente entre a teoria e a prática, esta vivenciada no final.

Decorrência disso, a formação de professores, nas últimas décadas, tem sido tema de discussões, reflexões e questionamentos. Isso decorre em função das mudanças em relação à sociedade e ao papel da escola que, nesse contexto, requer a ampliação de saberes que compõem o conhecimento profissional docente, para atender, principalmente, à diversidade - até pouco tempo excluída da educação sistematizada - presente nas instituições de ensino.

Nesse contexto da história da educação brasileira, o trabalho docente consistia em transmitir conhecimentos dogmáticos, de forma expositiva e repetitiva, aos seletos alunos, restando a eles a função de memorizar e reproduzir os conteúdos, em avaliações que objetivavam quantificar o

\footnotetext{
1. No curso de Didática eram ministradas as disciplinas de Psicologia da Educação, Fundamentos Biológicos da Educação; Fundamentos Sociológicos da Educação; Administração Escolar, Didática Geral e Especial.
} 
conhecimento. Essas práticas, ao longo dos anos, passaram a ser questionadas, em detrimento de outras necessidades, até então, ausentes no contexto escolar.

Dentre as práticas destacam-se a obrigatoriedade da educação da pré-escola ao ensino médio e as exigências pela melhoria da qualidade da aprendizagem, entre outras. Isso passou a requerer dos docentes uma gama de saberes oriundos de diferentes ciências, que precisam ser apreendidos, tanto na formação inicial quanto durante a vida profissional. Esses saberes são mobilizados em decorrência de problemas, necessidades e desafios que dizem respeito ao ensino e à aprendizagem, consequentemente, a formação inicial necessita de fundamentos teóricos e práticos que contribuam para a reelaboração dos saberes e a recriação da atividade docente.

Nessa perspectiva, a formação docente deve ser compreendida como: “[...] uma atividade profissional complexa, pois requer saberes diversificados. Isso significa reconhecer que os saberes que dão sustentação à docência exigem uma formação profissional numa perspectiva teórica e prática”. (VEIGA, 2008, p. 20).

Isso implica mudanças na concepção de conhecimento, de formação docente, de escola, de currículo, de organização do ensino, de aprendizagem, de avaliação, entre outros elementos que devem ocorrer, durante a formação inicial e continuada, a fim de que se possa superar a concepção de formação pautada na racionalidade técnica ${ }^{2}$, que predominou ao longo da história da educação brasileira. Para isso, são necessárias mudanças que perpassam os níveis da educação, mais especificamente as relacionadas com a formação inicial, em função das transformações científicas e tecnológicas ocorridas nas últimas décadas e que requerem outras aprendizagens, anteriormente 'dominadas' por uma parcela ínfima da população brasileira.

A construção de uma cidadania consciente requer conhecimentos que permitam ao sujeito transformar-se e intervir na sociedade e no mundo. Sabemos que as instituições de ensino não são as únicas responsáveis pela educação para a cidadania, mas são as que desenvolvem uma prática educativa planejada e sistemática, durante um longo e contínuo período de tempo, na vida das pessoas, principalmente em relação à Educação Básica.

Em função disso, tais instituições passam a ser reconhecidas pela sociedade como espaços de aprendizagem e de socialização dos conhecimentos que precisam subsidiar os alunos a ler criticamente diferentes textos, a agir autonomamente, a reconhecer a diversidade, a utilizar recursos

\footnotetext{
2 Racionalidade técnica - modelo que orientou e que, de certa forma, ainda está presente nas práticas pedagógicas, seja nos cursos de formação de professores, seja nas escolas. Nesse modelo o professor assume o papel de transmissor de conhecimento produzido por outros, mantendo, assim, uma relação linear entre conhecimento teórico e prático.
} 
tecnológicos, a comunicar-se em diferentes linguagens, a enfrentar desafios, a resolver situaçõesproblema, dentre outras habilidades.

Para que isso se efetive, necessitamos de profissionais com domínio dos conteúdos teóricos e procedimentos que contribuam para a construção de humanos. Nos dizeres de Pimenta:

[...] dentre os seres vivos, apenas os humanos produzam conhecimentos. [...] É o pensar que constitui o humano. O pensar, o refletir, o conhecer, o dominar a cultura acumulada, as formas de construção da sociedade, as tecnologias e as formas de construí-las. Isso é conhecimento. (PIMENTA, 2002, p. 31-32).

Nessa linha de pensamento, os fundamentos da teoria do ensino desenvolvimental propostos por Vygotsky e Davídov são fundamentais para auxiliar no processo de formação dos acadêmicos, uma vez que permitem compreender a constituição dos humanos e seu processo de aprendizagem, que ocorre pela internalização e apropriação dos conhecimentos produzidos pelos humanos.

Para se apropriar desses conhecimentos, os sujeitos necessitam da mediação didática dos mais velhos e/ou os mais experientes. Na educação escolar, quem ensina precisa ter o domínio dos conteúdos e isso implica uma formação acadêmica consistente, para que os futuros docentes medeiem didaticamente os conteúdos para os alunos que, por sua vez, deixem de ser passivos e participem efetivamente do seu processo de aprendizagem.

Isso significa ratificar a ideia de que a formação inicial deve zelar pela aprendizagem dos conhecimentos científicos junto aos acadêmicos que se preparam para o exercício docente; caso contrário, as dúvidas, os questionamentos, as interrogações ficam limitadas a respostas pontuais, ou, como se refere Davídov (1988) ao ensino empírico, transmitido pelos docentes, comprometendo a apropriação de conhecimentos que façam sentido para os alunos e sejam utilizados nos contextos da vida. Em outros dizeres, se a sociedade necessita de profissionais que dominem os conhecimentos científicos, culturais e éticos ou, como escreve Davídov (1988), que tenham um elevado nível de cultura geral e preparação profissional, os cursos de formação de professores devem primar pela formação do pensamento teórico, que ocorre por meio da construção de conceitos científicos.

Diferente do ensino teórico, o empírico contribui pouco para o desenvolvimento cognitivo e, em função disso, é comum prevalecer o discurso de carência individual, isto é, que os alunos 'não sabem nada'. Mudar essa concepção de ensinar requer um caminho pedagógico e didático que resulte na formação da generalização conceitual, no qual o professor:

[...] organiza a observação dos alunos, precisando o objeto da observação, orienta a análise para diferenciar os aspectos essenciais dos fenômenos daqueles que não o são e, finalmente, a 
palavra-termo, sendo associada aos traços distinguidos, comuns para toda uma série de fenômenos se converte em seu conceito generalizador. (DAVÍDOV, 1988, p. 102-103).

Nessa perspectiva, a diferença entre generalização de conceitos empíricos e teóricos está em que, para os primeiros, a aparência dos fenômenos é captada sensorialmente e tomada como essência e, nos segundos, são os aspectos essenciais, os traços comuns que estão presentes em uma série de fenômenos. Assim, a formação dos conceitos empíricos se fundamenta na prática de ensino que avança do particular para o geral e, para formar conceitos teóricos, o ensino deve partir do método dedutivo, para identificar o 'cerne' que origina o conteúdo e, a partir daí, deduzir as suas múltiplas propriedades particulares. Essa identificação do 'cerne' ajuda os alunos a reproduzirem mentalmente o objeto e a desenvolverem o pensamento teórico.

Para Davídov (1988), os conteúdos e métodos ensinados na escola têm ajudado os alunos a desenvolver o pensamento empírico ${ }^{3}$, ou seja, “[...] o pensamento que se realiza com ajuda das abstrações e generalizações de caráter lógico-formal somente leva a formar os chamados conceitos empíricos”. (DAVÍDOV, 1988, p. 104). Portanto, deixam de favorecer a formação da consciência e do pensamento teórico necessários para realizar generalizações científicas. Essa percepção implica refletirmos se os conhecimentos ensinados durante a trajetória de escolarização, principalmente da formação para o exercício do magistério, contribuem para ensinar na perspectiva da práxis educativa.

\section{ESTÁGIO SUPERVISIONADO: DESAFIO PARA OS ACADÊMICOS}

Com o objetivo de analisar as práticas de ensino dos acadêmicos, acompanhamos in locus o seu desenvolvimento. Inicialmente faremos considerações em relação aos acadêmicos, ao ambiente da sala de aula e, na sequência, ao planejamento, ao desempenho dos acadêmicos/estagiários, à organização do ensino e aprendizagem dos alunos durante o exercício da docência.

A maioria dos acadêmicos do Curso de Geografia optou pelo Curso, por ser noturno e por ter encerrado o Curso de Bacharelado. Embora nem todos manifestem o desejo de ser professor, a necessidade de trabalhar faz com que frequentem os cursos de licenciatura, únicos ofertados à noite.

Os acadêmicos possuem idade entre 22 e 40 anos; alguns retomaram os estudos, depois de um longo tempo distante das salas de aula. A maioria é filho de pais que não tiveram acesso a esse nível de ensino. Outro dado relevante é o de que a maioria dos acadêmicos estudou em escolas públicas,

\footnotetext{
${ }^{3}$ O pensamento empírico se limita ao dado aparente, o que impede uma maior compreensão das transformações, dos movimentos, da totalidade, das contradições, das variáveis próprias da formação dos conceitos científicos imprescindíveis à formação do pensamento teórico (MARZARI, 2016, p. 106).
} 
trabalha mais de trinta horas semanais e vive com uma renda mensal de dois a três salários mínimos. Embora possuam acesso à Internet, carecem de desenvolver o hábito da leitura, que se centra nos textos das disciplinas do Curso. Nesse sentido, a formação acadêmica fica restrita aos conteúdos abordados em sala de aula e isso faz com que careçam de outros referenciais teóricos e ambientes de aprendizagem que incluam "[...] leituras, discussões informais, troca de opiniões, participação em movimentos sociais, debates sobre temas atuais, exposições, espetáculos e outras formas de manifestação cultural e profissional” (BRASIL, 2001, p. 22).

As observações realizadas permitem dizer que as instituições de ensino pesquisadas vivenciam momentos de "tensão", no interior das salas de aula, dentre elas: - o enfraquecimento da autoridade do professor, que se evidencia nas constantes solicitações de silêncio em "tons de vozes elevados" para se fazer ouvir; nas conversas entre os alunos; na ausência e/ou desconhecimento de regras e valores de convivência; na inexistência de um ambiente propício para o desenvolvimento das atividades de ensino-aprendizagem; no aparente 'descompromisso' e/ou 'desinteresse', tanto com o processo de ensino quanto de aprendizagem. É nesse contexto que os acadêmicos iniciam suas primeiras experiências, isto é, realizam um curto período de observação, para que possam 'conhecer' a dinâmica da sala e preparem as aulas a serem desenvolvidas durante a regência.

Quando do exercício da docência, os acadêmicos/estagiários dificilmente conseguem realizar a regência, com aproveitamento, uma vez que naturalizaram o que vivenciaram durante a observação. Ou seja, que os alunos são assim mesmo, que a sala é 'agitada' e que o ensino pode acontecer naquele espaço, embora sendo muito pouco propício para obterem o mínimo de aprendizagem. Assim, resta aos acadêmicos/estagiários passar o conteúdo planejado, mesmo tendo a convicção de que a aprendizagem ficará comprometida, pois dificilmente conseguem se fazer ouvir, e a maioria dos alunos não presta atenção na aula. Embora alguns queiram aprender, acabam ficando 'desmotivados', ao não conseguirem ouvir as explicações do professor e nem de serem atendidos em suas dúvidas.

Em relação a essa situação, uma das estagiárias declara:

Tem aqueles alunos que não prestam a menor atenção no que você está explicando [pausa], mas a maioria deles fica atento ao que você está falando. Depois eles te procuram, perguntam alguma coisa. (Silvana, entrevista realizada no dia 18 de março de 2014).

Vale ressaltar que esse contexto de sala de aula descrito vai de encontro à perspectiva de que o professor deve ser

[...] valorizado no seu papel de autoridade que orienta e favorece o processo de ensinar e de aprender. É pela presença do professor que se torna possível uma 'ruptura' entre a experiência 
pouco elaborada e dispersa dos alunos em direção aos conteúdos culturais universais permanentemente reavaliados face às realidades sociais. (VEIGA, 2002, p. 67)

Se, por um lado, as salas de aulas observadas são pouco propícias para o processo de ensinoaprendizagem, por outro, os acadêmicos apresentam fragilidades teóricas em relação à preparação básica para o exercício da docência, tanto em relação ao domínio dos conteúdos quanto das questões didático-pedagógicas que compõem o exercício da profissão. Isso se evidencia na elaboração do plano de aula, na transmissão de definições, na ênfase no livro didático, nos exercícios, nas avaliações, na administração do espaço, no relacionamento com os alunos, entre outras atividades.

Os planos de aula dos estagiários, em sua maioria, contemplam os dados de identificação, a ementa, os objetivos geral(is) e específicos, procedimentos de ensino, recursos, avaliação e referências; porém os acadêmicos precisam ter clareza da diferença entre plano de ensino e de aula. Uma leitura dos planos e as observações em sala indicam uma predominância na centralidade do professor, que se sente na obrigação de transmitir os conteúdos fundados apenas em suas definiç̧ões e não na formação dos conceitos. Esta tem sido uma prática recorrente entre os acadêmicos observados que adentram a sala de aula: anunciam o conteúdo e iniciam a leitura e/ou explicação dos conteúdos do livro didático, seguidas de comentários sobre o que foi lido ou explicado. Poucos são os alunos que tentam acompanhar essas atividades, uma vez que a maioria conversa em tom elevado, alguns entram na sala e dela saem, chamando a atenção das mais diferentes formas.

Nesse ambiente de certa 'agitação' a aula acontece e, quando o acadêmico/estagiário termina de expor os conteúdos, indica a página dos exercícios que estão no livro; outras vezes, entrega folhas mimeografadas e/ou passa as tarefas no quadro, em forma de questionários, questões de relacionar colunas e caça-palavras, que exigem pouco desenvolvimento de raciocínio dos alunos. Essa forma de procedimento ocupa apenas uma parte da aula, em média dois terços; no restante do tempo, os alunos ficam ociosos.

Os acadêmicos do curso de Letras que desenvolveram a regência, referente ao segundo semestre de 2013, no contexto da universidade, também propuseram tarefas semelhantes. Inicialmente explicavam o conteúdo da aula para os professores responsáveis pelo estágio e alguns acadêmicos que apresentariam a aula naquele dia e, na sequência, distribuíam os exercícios de fixação que seriam recolhidos para atribuição de uma nota. Isso ratifica o fato de que "[...] cada vez mais alunos não vão à escola para aprender, mas apenas para passar de ano, sem preocupação nem com a atividade intelectual, nem como patrimônio humano". (CHARLOT, 2013, p. 180). 
Vale ressaltar que, tanto nas aulas ministradas pelos acadêmicos/estagiários do Curso de Letras, como pelos do Curso de Geografia, foram poucos os momentos em que envolviam os alunos, quando em atividade de docência, a fim de que entrassem em atividade de aprendizagem. Essas formas de agir e/ou lidar com o conhecimento têm sido um indicativo de que muitos alunos chegam ao ensino superior e dele saem sem terem desenvolvido habilidades de pensamento que deveriam ter sido ensinadas, desde os primeiros anos de escolaridade. Com esse nível de escolarização, os alunos chegam ao ensino superior com carências concretas que acabam comprometendo o êxito esperado de um universitário e, por sua vez, o nível superior acaba, na maioria das vezes, ratificando esse mesmo processo de ensino-aprendizagem.

Consequência disso, os acadêmicos/estagiários, quando no exercício da docência, acabam reproduzindo a forma de ensinar que aprenderam, no transcorrer da trajetória de vida escolar. Somase a isso, a fragilidade e/ou ausência de políticas públicas voltadas para a formação continuada dos docentes universitários, o que, segundo Marcelo Garcia (1999b), acaba por ratificar uma tendência de conservar e manter o que supostamente está funcionando. Isso faz com que se mantenha uma proposta de formação inicial fundamentada na concepção tradicional, em que se entende que, para ser professor universitário, basta ter domínio de uma determinada área/disciplina do conhecimento, geralmente aquela que resulta em dissertações e teses.

Sabe-se que a maioria dos professores que atuam nos cursos de licenciatura são mestres e doutores, mas isso não significa dizer que estão isentos da necessidade e da responsabilidade com a formação continuada, principalmente porque um número significativo deles possui formação em bacharelado e estão formando licenciados, para atuar na educação básica. Nos dizeres de Veiga:

A competência científico-pedagógica, embora deva ter seu início nos programas de pósgraduação, aprimorar-se-á nos processos de formação continuada que ocorrem no âmbito da ação coletiva de construção, desenvolvimento e avaliação dos projetos pedagógicos de curso. (VEIGA, 2012, p. 45)

Nessa perspectiva, investir na formação continuada tem sido imprescindível para compreender, propor e intervir nas políticas públicas e na realidade das escolas, principalmente nas públicas, que atendem a uma rica diversidade de alunos, muitos deles, até pouco tempo, excluídos do acesso à educação de qualidade. Para isso, é necessário “[...] construir caminhos possíveis para nos aproximarmos de políticas educacionais que rompam com a repetição, com a mesmice, com as rotinas burocráticas que atingem não só a educação superior e a educação básica, mas o próprio futuro da nação". (VEIGA, 2012, p. 16) 
Na avaliação de Eliane (Eliane, entrevistada no dia 21 de março de 2014), os professores do Curso de Geografia são bons, embora, em algumas disciplinas, esqueçam que estão em um Curso de Licenciatura e deixem de estabelecer relações entre os conceitos de geografia com o que precisa ser ensinado, nos diferentes anos do ensino fundamental e médio.

Rever concepções de ensino é possível, desde que se questionem as verdades cristalizadas e se estabeleça um diálogo entre os envolvidos no processo de ensinar e aprender que leve às mudanças nas estruturas de pensamento. Para que isso ocorra é necessário um planejamento que tenha, segundo Davídov (1988), uma série de ações, operações e tarefas que permitem ao aluno internalizar conteúdos escolares e se apropriar deles. Assim, ao completar as ações, os alunos se apropriam dos conceitos, o que ocorre quando são capazes de estabelecer relações entre sua atividade de aprendizagem e os conceitos em estudo.

Como a maioria dos planejamentos de ensino e das aulas se pauta numa concepção de que o professor é aquele que detém os conhecimentos e deve transmiti-los aos alunos, considerados sujeitos passivos, que devem absorver e reproduzir tais conhecimentos, de forma empírica, acaba-se comprometendo a capacidade de análise, de síntese e de julgamento dos diferentes fenômenos da realidade.

Vale ressaltar que todas as entrevistadas discorreram sobre as dificuldades iniciais do curso de Geografia, principalmente em relação ao quadro de professores e da infraestrutura. Outro ponto destacado refere-se à pouca convivência com o espaço escolar, durante o curso, mesmo que para isso se tenha uma carga-horária de 400 horas de prática, como componente curricular que, também, deveriam aproximar os acadêmicos do contexto escolar. No Curso de Geografia alguns professores que desenvolvem as práticas fazem simulações dentro da própria sala de aula. Em relação a isso, as alunas fazem a seguinte avaliação:

Eu acho que é um pouquinho diferente [riso] é diferente você pagar e falar para seus colegas que você já conhece e vai passar [conteúdo] de uma forma que todos já sabem como funciona. Passar isso para os alunos e mais complicado. Igual eu vi também na minha sala de ensino fundamental que tinha alunos que não sabiam nem ler, praticamente, não sabiam interpretar uma pergunta. Então eles precisam de uma atenção a mais. (Eliane, entrevista realizada no dia 21 de março de 2014).

[...] dentro da sala de aula você vai ter contato com vários alunos que você não conhece, não sabe a realidade deles, não sabe os problemas que eles têm em casa, não sabe se eles estão preparados para receber o conteúdo que você vai passar. Porque nós não sabemos nada sobre a vida do aluno. Então é complicado você dar aula na academia para seus colegas, que é diferente de estar dentro de uma sala de aula. [...]. (Silvana, entrevista realizada em 18 de março de 2014) 
No geral, os acadêmicos/estagiários, depois de passarem pela experiência da regência, percebem que estar mais próximo da escola é fundamental para a formação acadêmica. Além disso,

[...] estar mais em contato com a escola para entender a realidade da escola porque tem muitos desafios, muitos obstáculos dentro da escola e, as vezes, a gente deixa para ver isso só no final do curso, quando vai para o estágio. Então eu acredito que desde o primeiro ano o professor tem que mostrar essa realidade para o aluno e fazer com que ele elabore projetos já nas escolas. (Eliane, entrevista realizada no dia 21 de março de 2014)

No geral, os acadêmicos/estagiários do Curso de Geografia percebem que sentir o cotidiano da escola é fundamental para sua formação. Afirmavam que “[...] estar mais em contato com a escola para entender a realidade da escola porque tem muitos desafios, muitos obstáculos dentro da escola e, às vezes, a gente deixa para ver isso só no final do curso, quando vai para o estágio [...]”. (Eliane, entrevistada no dia 21 de março de 2014). Assim,

[...] o conhecimento da realidade escolar através dos estágios não tem favorecido reflexões sobre uma prática criativa e transformadora nem possibilitado a reconstrução ou redefinição de teorias que sustentem o trabalho do professor. (PICONEZ, 1991, p.17)

Convém lembrar que isso pode não ter o mesmo significado para os ingressantes nos cursos de licenciatura, uma vez que nem todas as disciplinas que constituem o currículo de formação acadêmica conseguem enfatizar a dimensão prática, fazendo com que essa problemática fique reduzida aos espaços da universidade e/ou no desenvolvimento de ações pontuais. Somente quando o acadêmico precisa exercer a docência é que percebe o quanto é importante vivenciar os diferentes espaços escolares para conhecer a totalidade que envolve o processo educativo, ou seja, entender as políticas públicas da educação básica; conhecer a sua diversidade; participar da formação continuada e das reuniões pedagógicas; compreender a rotina e o espaço da escola, para se iniciar na atividade docente e não simplesmente realizar uma etapa obrigatória e pontual necessária para a conclusão do curso.

Além disso, é preciso ampliar as discussões sobre o “[...] desenvolvimento humano e a forma como diferentes culturas caracterizam as diferentes faixas etárias e as representações sociais e culturais dos diferentes períodos: infầncia, adolescência, juventude e vida adulta”. (BRASIL, 2001, p. 45). Compreender o processo de aprendizagem e desenvolvimento dos diferentes períodos ajuda a lidar com a diversidade dos alunos e a educar na perspectiva da inclusão escolar. Portanto, o exercício da docência requer, além do domínio dos conhecimentos específicos que possibilitem a sistematização e o aprofundamento de conceitos, a compreensão das questões envolvidas no exercício da docência, como a autonomia na tomada de decisões e responsabilidade diante das opções feitas. 
Existe nas ações dos acadêmicos/estagiários uma preocupação com as atividades avaliativas atribuição de notas - em detrimento do processo de aprendizagem dos conteúdos. Talvez isso aconteça em decorrência das práticas vivenciadas por eles que se reduzem:

[...] a observar os professores em aula e imitar esses modelos, sem proceder a uma análise crítica fundamentada teoricamente e legitimada na realidade social em que o ensino se processa. Assim, a observação se limita à sala de aulas em análise do contexto escolar, e espera-se do estagiário a elaboração e execução de 'aulas-modelo'. (PIMENTA, LIMA, 2004, p. 36).

Reconhecer as incompletudes em relação aos conhecimentos e às práticas educativas mostra a vivacidade docente, uma vez que, para viver, deve-se, nos dizeres de Freire (1998), reconhecer a incompletude humana e ter a consciência da própria inconclusão. Com isso, o sujeito viabiliza sua educabilidade. É essa busca constante para completar-se que leva o sujeito a dirigir-se ao outro, como o caminho possível de uma completude sempre impossível, mas desejável. É isso que motiva o sujeito a buscar novas possibilidades de pensar as práticas formativas, uma vez que "[...] os professores precisam dominar cada vez mais os conteúdos curriculares, os processos de ensino e de aprendizagem, isto é, especializarem-se no 'o que', no 'como' e no 'para que' se ensina e se aprende”. (MONTOAN, 2012, p. 93).

No entanto, isso não significa que o ato de ensinar seja apenas a transmissão do conhecimento, mas " [...] requer que o educador medeie o conhecimento elaborado historicamente a partir dos aportes teórico-metodológicos da didática, da psicologia da educação e das metodologias de ensino". (BERNADES, 2012, p. 82).

Por último, Libâneo (2012) diz que a aprendizagem da profissão docente requer: domínio teórico do conteúdo da matéria a ser ensinada; apropriação de metodologias de ensino que envolvem, de forma geral, a didática e, principalmente as didáticas disciplinares; conhecimentos das características individuais e socioculturais dos alunos, uma vez que a atividade de aprendizagem do aluno precisa desencadear mudanças qualitativas em seu desenvolvimento; conhecimento das práticas socioculturais e institucionais em que os alunos estão envolvidos e as formas como elas atuam na sua motivação e na aprendizagem. Assim, as convicções ético-políticas estão imbricadas tanto no papel educativo do professor, no sentido de orientar o ensino dos conteúdos necessários à formação da personalidade, quanto na ajuda efetiva aos estudantes para que aprendam a colocar-se diante da realidade e reagir a ela, numa direção emancipatória. 


\section{CONSIDERAÇÕES FINAIS}

Estamos cientes de que a formação inicial não começa com o ingresso dos alunos em um curso de licenciatura e nem se encerra com sua conclusão. Nem por isso os acadêmicos devem concluir seu curso com tantas carências em relação ao domínio dos conhecimentos didáticopedagógicos e, particularmente, dos conteúdos específicos da área de conhecimento.

Esse pouco domínio dos conhecimentos, ao que tudo indica, está relacionado com a didática utilizada pelas diferentes disciplinas, isto é, elas são ministradas de forma fragmentada e os conteúdos são, prioritariamente, ensinados por meio de definições, o que acaba comprometendo a práxis educativa reproduzida pelos acadêmicos em seu estágio. Resultado disso é que os alunos da educação básica dificilmente conseguem se apropriar dos conteúdos para avançar no processo de aprendizagem, o que reforça a tese de que os acadêmicos/estagiários aprendem os conteúdos empiricamente e dificilmente conseguem significá-los, para que façam sentido para quem precisa apreender. Consequência disso é o fato de os alunos terem dificuldades em relacionar criticamente o que aprendem na escola com as situações concretas da vida.

Superar essa fragilidade requer que os acadêmicos/estagiários aprendam o processo de produção dos conhecimentos que ensinam, isto é, que tenham noções básicas dos contextos e dos métodos de investigação da ciência, para que não se tornem meros repassadores de informações pontuais. Para isso, é preciso superar a predominância de aulas fundadas na exposição de definições, na crença de que se aprende somente com o professor e na reprodução de exercícios que pouco contribuem com o desenvolvimento cognitivo/mental. Essa prática dificulta a interação entre os alunos que, nos dizeres de Vygotsky (2001), são fundamentais para o desenvolvimento cognitivo, pois a apropriação do conhecimento social, histórico e culturalmente construído ocorre no sentido da relação interpessoal para a intrapessoal.

Podemos dizer que os acadêmicos, com raras exceções, reproduzem, durante o estágio, as práticas vivenciadas na trajetória escolar e, quando não, ratificadas, no ensino superior. Assim, mantemos um modelo de educação que naturaliza a exclusão, ao se 'isentar' das responsabilidades com o processo de aprendizagem dos alunos, principalmente dos que mais necessitam da escola para apreender os conhecimentos científicos. Para isso, os acadêmicos precisam conhecer melhor os conteúdos curriculares da educação básica e das didáticas próprias das disciplinas específicas, para poderem ensinar de tal forma que a aprendizagem seja significativa e possa ser utilizada em diferentes contextos.

Se pretendemos que a formação promova o compromisso do professor com as aprendizagens de seus futuros alunos, é fundamental que os formadores também assumam esse compromisso em 
relação aos futuros professores, começando por levar em conta suas características individuais, experiências de vida, inclusive, as profissionais". (BRASIL, 2001, p. 32).

Em função disso, as práticas desenvolvidas pelos acadêmicos devem ser repensadas pelos professores envolvidos na sua formação, uma vez que os acadêmicos, ao vivenciarem o contexto da escola, acabam levando para a universidade situações, muitas vezes, pautadas no discurso empírico que precisa ser ampliado teoricamente pelos professores formadores. É preciso que os formadores de 'novos' professores tenham a consciência da necessidade de se prepararem pedagogicamente, o que os tornaria melhores professores, ainda que sejam bons profissionais em sua formação de origem. Nessa perspectiva, o bom professor deve ser capaz de refletir sobre a educação, em sua totalidade, e isso implica ser capaz de ensinar, promovendo aprendizagem. Para tanto, os conhecimentos das pesquisas pedagógicas, assim como os métodos e técnicas de ensino, podem auxiliá-los nessa 'tarefa'. Nessa perspectiva o professor deve dar menos respostas e fazer mais perguntas, para que os alunos desenvolvam o pensamento cognitivo.

Para superar essa prática são imprescindíveis mudanças na concepção de ensinoaprendizagem, ou seja, é preciso gastar mais tempo discutindo o que fazer, para que os alunos apreendam os saberes escolares, ao invés de excluí-los e/ou reprová-los. Além disso, o trabalho do professor, em sua essência, nos dizeres de Fichtner (2012), não está propriamente no que ele faz, mas no que ele é pessoalmente. Nesse sentido, não são somente os métodos, as técnicas, as ações e as palavras de um professor que são decisivos, mas o seu espírito, sua autenticidade e sua credibilidade.

É preciso que as instituições formadoras e as escolas de educação básica, que recebem os estagiários/acadêmicos, articulem as ações a serem realizadas pelos acadêmicos/estagiários, a fim de que ambas possam avaliar e intervir no processo de formação acadêmica e, também, nos contextos institucionais.

Outra questão a ser pontuada diz respeito à proximidade que deve existir entre os cursos de licenciatura e a educação básica. Isto é fundamental para que os acadêmicos/estagiários conheçam as políticas públicas, os projetos pedagógicos, as diretrizes curriculares, a forma de gestão escolar, as modalidades de ensino, a diversidade presente na sala de aula, as condições de trabalho, entre outros elementos, para que possam se preparar para o exercício da docência e serem agentes de mudanças. Para isso, é necessário realizar estudos, formações e pesquisas na Educação Básica para produzir conhecimentos que contribuam para a melhoria do processo de ensino-aprendizagem e, consequentemente, da formação de professores. 
É imprescindível, pois: - formação continuada dos docentes que atuam nos cursos de licenciatura, a fim de que tenham um espaço para discutir, criticar e apresentar propostas para a melhoria, tanto das políticas públicas quanto do processo de ensino-aprendizagem, tanto na educação básica quanto nos cursos de formação de professores; - elaboração de planejamentos interdisciplinares e utilização de diferentes procedimentos de ensino para que os acadêmicos possam vivenciar, "[...] ainda durante a formação acadêmica, outras perspectivas de ensino, mais voltadas para a qualidade do desenvolvimento cognitivo dos alunos” (MARZARI, 2016, p. 363); reelaboração dos projetos pedagógicos dos cursos de licenciatura, para que possam atender às exigências da formação de professores para atuar nas diferentes etapas e modalidades da educação básica; - criação de vínculos com as instituições de educação básica, para que os acadêmicos possam vivenciar o contexto escolar e trazer para a academia questões que, com mediação didática dos professores formadores, sejam levados a realizar a práxis educativa.

Por fim, precisamos registrar que os problemas levantados, durante a investigação, não são somente relacionados aos processos de formação educacional, mas também das políticas públicas de educação pouco consistentes em relação ao exercício do magistério; a desvalorização da profissão docente; as condições de trabalho pouco satisfatórias e condizentes com a atividade de ensino; as exigências que são requeridas do docente; o pouco interesse e envolvimento das universidades com as questões referentes à educação básica e à formação de professores para esse nível da educação, entre outros problemas que têm desmotivado alunos e professores. 


\section{REFERÊNCIAS}

BERNARDES, Maria Elixa Mattosinho. Pedagogia e mediação pedagógica. In: LIBÂNEO, José Carlos; ALVES, Nilda (Orgs.). Temas de pedagogia: diálogos entre didática e currículo. São Paulo: Cortez, 2012.

BOGDAN, Roberto C.; BIKLEN, Sari K. Investigação qualitativa em educação. Trad. Maria João Alvarez; Sara Bahia dos Santos; Telmo Mourinho Baptista. Porto: Porto Editora, 1994.

BRASIL. Resolução CNE/CP 2, de 19 fev. 2002. Diário Oficial da União, Brasília, p. 9, Seção 1. 04 mar. 2002.

CHARLOT, Bernard. Da relação com o saber ás práticas educativas. São Paulo: Cortez, 2013. (Col. Docência em formação: saberes pedagógicos).

DAVÍDOV, Vasili Vasilievich. La enseñaza escolar y eldesarollo psiquico: investigación psicológica, teórica y experimental. Moscou: Editorial Progreso, 1988.

FICHTNER, Bernhard. O conhecimento e o papel do professor. In: LIBÂNEO, José Carlos; ALVES, Nilda (Orgs.). Temas de pedagogia: diálogos entre didática e currículo. São Paulo: Cortez, 2012.

FREIRE, Paulo. Pedagogia da Autonomia: saberes necessários à prática educativa. São Paulo: Paz e Terra. 1998.

LIBÂNEO, José Carlos. Ensinar e aprender, aprender e ensinar: o lugar da teoria e da prática em didática. In: LIBÂNEO, J.C.; ALVES, N. (Orgs.). Temas de pedagogia: diálogos entre didática e currículo. São Paulo: Cortez, 2012.

LÜDKE, Menga; ANDRÉ, Eliza D. A. Pesquisa em educação: abordagens qualitativas. São Paulo: EPU, 1986.

MARCELO GARCIA, C. Formação de professores: para uma mudança educativa. Porto: Porto, $1999 \mathrm{~b}$.

MARZARI, Marilene. Ensino e aprendizagem de didática no curso de pedagogia: contribuições da teoria desenvolvimental de V. V. Davídov. 2010. Jundiaí: Paco Editorial, 2016.

MONTOAN, Maria Teresa Eglir. Caminhos Pedagógicos de Educação Inclusiva. In: GAIO, Roberta; MENEGHETTI, Rosa G. Krob (Orgs.). Caminhos Pedagógicos da Educação Especial. Petrópolis: Vozes, 2012.

PICONEZ, Stela C. Bertholo. A prática de ensino e o estágio supervisionado: a aproximação da realidade escolar e a prática da reflexão. In: FAZENDA, Ivani C.A. et. al.; PICONEX, Stela C. Bertholo (Coord.). A prática de ensino e estágio supervisionado. 11. ed. Campinas: Papirus, 2005. (Col. Magistério: Formação e Trabalho Pedagógico).

PIMENTA, Selma G. De professores, pesquisa e didática. Campinas: Papirus, 2002. (Col. Entre Nós Professores).

; LIMA, Maria Socorro L. Estágio e docência. São Paulo: Cortez, 2004.

VEIGA, Ilma P. Alencastro. A aventura de formar professores. 2. ed. Campinas: Papirus, 2012. (Col. Magistério: Formação e Trabalho Pedagógico).

VEIGA, Ilma P. Alencastro. (Org.). Profissão docente: novos sentidos, novas perspectivas. Campinas: Papirus, 2008.

A prática pedagógica do professor de didática. 7. ed. Campinas: Papirus, 2002.

VYGOTSKY, Lev Semenovich. A construção do pensamento e da linguagem. São Paulo: Martins Fontes, 2001. 


\section{RESUMO}

Este artigo tem como objetivo analisar as práticas de ensino desenvolvidas pelos acadêmicos dos cursos de licenciatura em Letras e em Geografia, no estágio supervisionado, na etapa de regência nos anos finais do Ensino Fundamental, nas escolas da rede estadual, em Barra do Garças/MT, para o que a metodologia qualitativa com os procedimentos de observação, entrevista e análise de documentos foi fundamental. 0 referencial teórico pautou-se em autores como Veiga, Pimenta, Vygotsky, Davídov, entre outros. Os resultados indicam que os acadêmicos reproduzem as práticas de ensino que vivenciaram durante a formação, o que implica dizer que ensinam a partir da exposição da definição de conteúdos e, na sequência, de uma lista de exercícios de fixação que a maioria dos alunos responde para obter notas.

Palavras-chave: Formação docente. Práticas de ensino. Aprendizagem.

\section{MAJOR COURSES: THE PRACTICE OF MODERN LANGUAGES (PORTUGUESE) AND GEOGRAPHYSTUDENTS}

\section{ABSTRACT}

This article aims to analyze the educational practices developed by major coursesstudents of Modern Languages (Portuguese) and Geography, during their supervised practicein the final years of Elementary School in state schools in the city of Barra do Garças/MT. The qualitative methodology and observation procedures, interviews and document analysis enabled an analysis of academic teaching practices. Authors such as Veiga, Pimenta, Vygotsky, Davídov, among others, marked the theoretical framework. The results indicate that academic students reproduce teaching practices that they have experienced during graduation, which implies that they teach from the exposure setting of content definition and, as a result, a list of fixation exercises that most students respond for obtaining their grades.

Keywords: Teacher training. Teaching Practices. Learning.

Submetido em Ago./2016 Aprovado em Dez./2016 